\title{
Juvenile Psoriatic Arthritis (JPsA) clinical features and outcome of
} I 9 patients

\author{
Y Butbul Aviel*, PN Tyrrell, BM Feldman, RM Laxer, RK Saurenmann, \\ L Spiegel, B Cameron, S Tse and ED Silverman
}

Address: Division of Rheumatology, The Hospital for Sick Children, Department of Pediatrics, University of Toronto, Toronto, Ontario, Canada * Corresponding author

\author{
from $15^{\text {th }}$ Paediatric Rheumatology European Society (PreS) Congress \\ London, UK. 14-17 September 2008 \\ Published: 15 September 2008 \\ Pediatric Rheumatology 2008, 6(SuppI I):P42 doi:I0.II86/I546-0096-6-SI-P42
}

This abstract is available from: http://www.ped-rheum.com/content/6/SI/P42

(c) 2008 Aviel et al; licensee BioMed Central Ltd.

\section{Objective}

To determine the long-term outcome of a single center cohort of children with JPsA.

\section{Methods}

Clinical records of 122 patients meeting the Vancouver or ILAR criteria for JPsA were reviewed. Patients were divided into 4 groups depending on their clinical features: a)Oligoarticular, b)RF(-) polyarticular, c) RF(+) polyarticular and d)enthesitis related arthritis (ERA). Patient characteristics and clinical features at onset and during follow-up were determined.

\section{Results}

The cohort consisted of 119 patients, 59(49.6\%) had polyarticular course, 54(47.8\%) were RF(-) and $4(3.3 \%)$ $\mathrm{RF}(+), 44$ patients(38.3\%) had oligoarticular course and $16(13.4 \%)$ ERA.

At diagnosis patients with ERA were older as compared to patients with oligoarticular and polyarticular course (11.6 \pm 2.2 years vs $7.7 \pm 4.3$ years and $7.1 \pm 4.5$ years respectively $\mathrm{p}=0.001$ ).

Patients with polyarticular course had more MCP, PIP and wrist involvement when compared to patients with oligoarticular course and with ERA ( $\mathrm{p}<0.001$ for all).
Patients with ERA had significantly more hip and sacroiliac involvement compared to the other groups ( $\mathrm{p}<0.001$ for both).

Nail changes was seen in 66 patients (57\%) and was associated with DIP involvement at presentation $(\mathrm{p}=0.0034)$.

\section{Outcome}

Time to first inactive disease period on but not off therapy was significantly longer among patients with polyarticular disease when compared to the oligoarticular and the ERA groups ( $\mathrm{p}=0.016$ and $\mathrm{p}=0.48$ respectively).

Patients with polyarticular had more contracture during follow-up when compared to patients with oligoarticular and with ERA ( $\mathrm{p}=0.01)$

\section{Conclusion}

Patients with JPsA compromised from three distinct group of patients.

Most patients with JPsA will achieve inactive disease and only minority will have long lasting contracture. 